\title{
INEQUALITY OF BLOOD PRESSURE IN THE BRACHIAL ARTERIES, WITH ESPECIAL REFERENCE TO DISEASE OF THE ARCH OF THE AORTA
}

\author{
By HORACE M. KORNS AND P. H. GUINAND \\ (From the Department of Internal Medicine, State University of Iowa, Iowa City)
}

(Received for publication August 24, 1932)

It has been tacitly assumed that in normal persons the blood pressure and the volume of the pulse are equal in the right and left brachial and carotid arteries, and as a corollary, that sphygmic inequality in these arteries is evidence of disease of the aorta, provided that peripheral causes of partial arterial occlusion, such as encroachment of the clavicle on the subclavian artery, cervical ribs, thrombosis, embolism, and arteriosclerosis, as well as developmental anomalies of the aorta and its main branches, can be excluded. In other words, the occurrence of a lower pressure and smaller pulse on one side is taken to mean that some pathological process, such as syphilitic aortitis, has brought about narrowing of a main branch of the aorta at its origin. This is illustrated by the following case.

Case 1. A man 45 years of age complained of nocturnal cardiac dyspnea, weakness, and air hunger on exertion. Physical examination disclosed the Corrigan pulse, selective left ventricular hypertrophy, and characteristic auscultatory signs, of pure aortic regurgitation. Except for a loud aortic systolic murmur, there were no indications of enlargement of the ascending or transverse portions of the aorta, but the innominate artery was very accessible in the retro-manubrial space, and there was parasternal dullness both to the right and left in the first intercostal space. The carotid pulses were of equal volume, but the pulse in the right subclavian and its branches was at all times strikingly smaller than that in the left. The brachial arterial pressures were recorded on two occasions only (Figure $1 A$ ), partly because the patient contracted pneumonia immediately after his admission to the hospital, and was too ill thereafter to be disturbed unnecessarily. Additional features of the case were premature senility, generalized arteriosclerosis, absence of any history of rheumatic fever, and a strongly positive blood Wassermann reaction. Obviously the patient had syphilitic aortitis with aortic regurgitation, and the relatively low right brachial pressure made one suspect that the mesarteritis had extended throughout the innominate and partially obstructed the orifice of the subclavian. This suspicion was confirmed by postmortem examination, which showed that the diameter of the right subclavian orifice had been reduced one-third. The right carotid was normal, and although the mesarteritis had entered the left subclavian and carotid it had not encroached upon their lumina. 


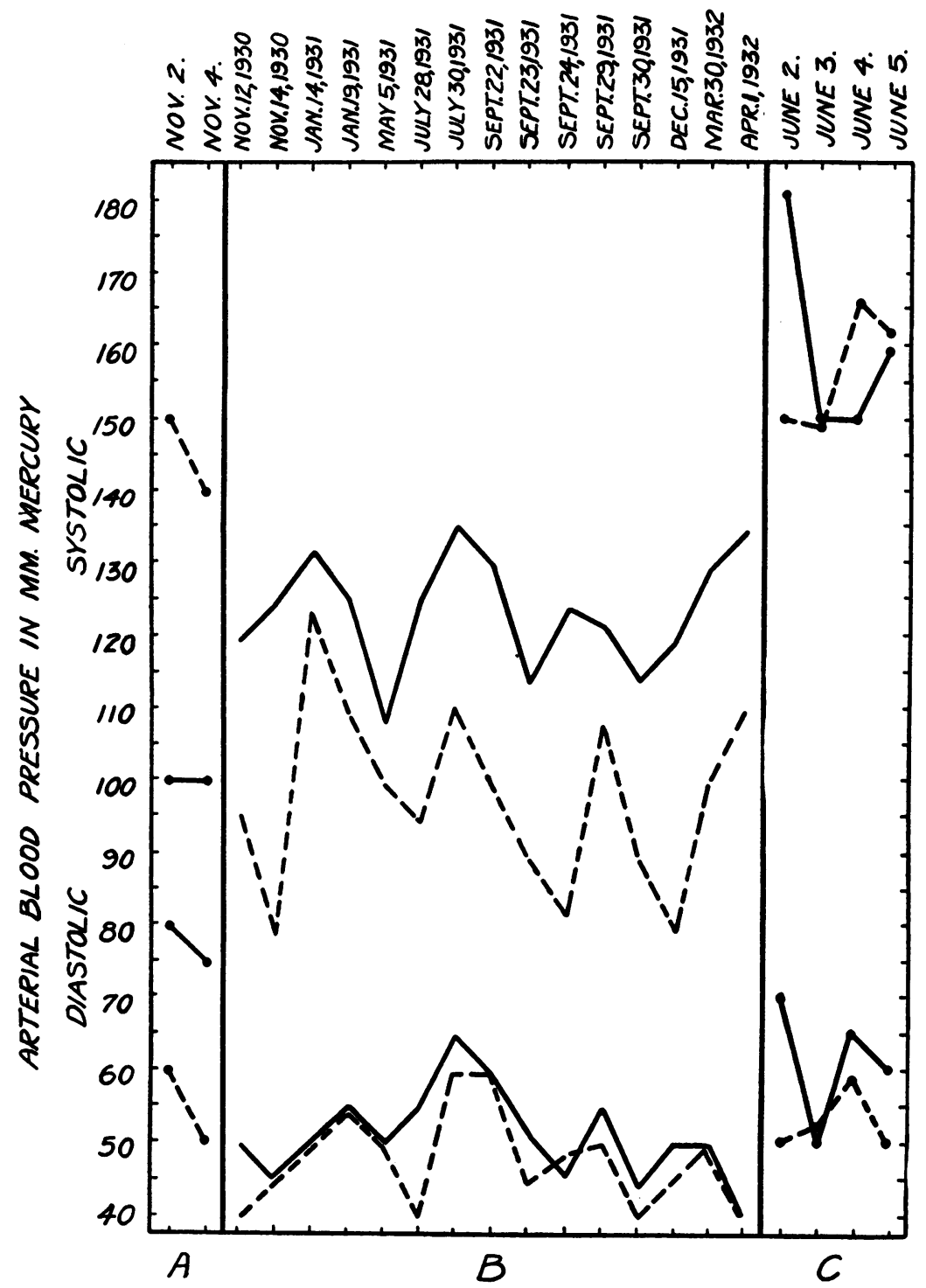

Fig. 1. Arterial Blood Pressure in mm. Hg Right arm,

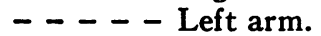

A. Case 1. W. F., male, age 45 .

B. Case 2. R. B., male, age 49.

C. Case 4. B. A., male, age 48. 
Unfortunately, not all cases are so satisfactory. To begin with we shall exclude from consideration manifest aneurysm of the aorta, together with the hydrodynamic and mechanical alterations peculiar to aneurysm, and confine our attention to lesions which present genuine diagnostic difficulties with respect to etiology and pathological physiology and anatomy. The following cases illustrate some of the principal aspects of the problem.

Case 2. A man 49 years of age without complaints referable to his heart presented the usual signs of aortic regurgitation, except that his pulse, although possessed of the requisite volume, exhibited a prominent anacrotic interruption which effectively obscured whatever celerity it might have had. The ascending and transverse portions of the aorta were enlarged, as attested by the ready accessibility of the innominate artery behind the manubrium, a tracheal tug, a palpable systolic impulse over the aortic area, parasternal dullness in the second intercostal space to the left, and an aortic systolic murmur. The carotid pulses were equal, but the pulse in the left subclavian and its branches was much smaller than in the right, and the left brachial pressure was correspondingly low (Figure $1 B$ ). There was nothing in the history to suggest either rheumatic fever or syphilis, and the blood Wassermann reaction was negative. After two months of vigorous anti-syphilitic treatment the disparity of pulse and pressure had disappeared (Figure 1B, January 14, 1931), which seemed to fortify the diagnosis of syphilitic aortitis. Six months later, however, despite continued treatment, the disparity had returned to its original magnitude, where it remained subsequently (Figure $1 B$, July 28,1931 , to April 1, 1932).

The next case came under observation just at the time when we were puzzled by the reappearance of the original sphygmic inequality in Case 2 and added the finishing touch to our perplexity.

Case 3. The patient was a man of 33 years who presented the cardinal signs of aortic regurgitation, without dynamic evidence of aortic stenosis, but with an aortic systolic murmur. With the possible exception of this murmur, there was nothing to indicate dilatation or elongation of the aorta - a fact which did not lessen the difficulty of discovering the etiology of his heart disease. No history of rheumatic fever or syphilis could be obtained, and the blood Wassermann reaction was negative. At first, with equal carotid pulses, the left brachial pressure was considerably lower than the right, which suggested syphilitic aortitis at the orifice of the left subclavian artery, and, by inference, a syphilitic etiology for the aortic regurgitation. However, it soon became apparent that the pressure inequality varied in degree from day to day, and was of ten wanting entirely (Figure 2).

The next case is important because it illustrates the conjunction of temporary sphygmic inequality in the brachial arteries with widespread mesaortitis syphilitica.

Case 4. A man 48 years of age entered the hospital with all the manifestations of bilateral heart failure, but in spite of his cardiectasis and generalized stasis it was possible to make a satisfactory diagnosis of syphilitic aortitis and aortic regurgitation. The arterial pulse was of large volume, although its 
celerity was somewhat obscured by an anacrotic interruption. The left ventricle was greatly enlarged, and the aortic second sound was partially replaced by an aortic diastolic murmur. A systolic impulse and diastolic impact were palpable over the aortic area, the innominate was abnormally accessible behind the manubrium, and there was parasternal dullness which

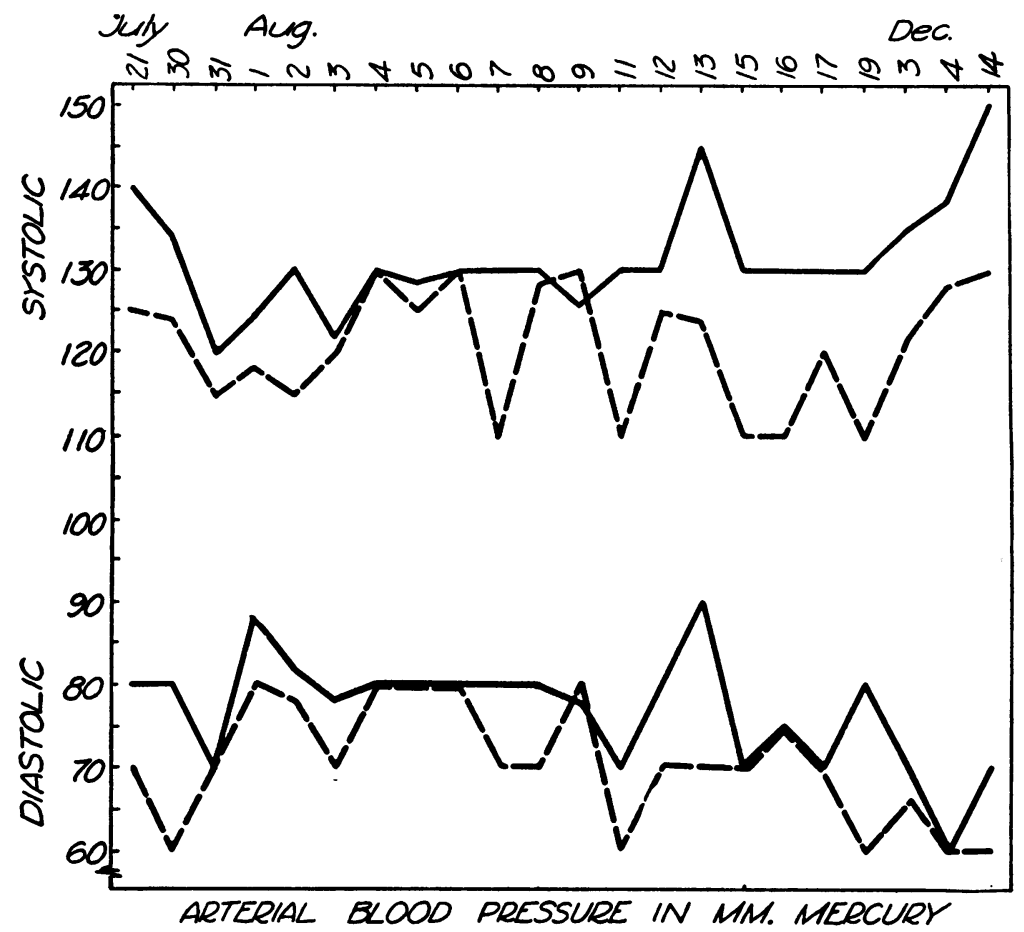

Fig. 2. Arterial Blood Pressure in mM. Hg

$$
\begin{aligned}
& \text { Right arm, } \\
& \text { - - - Left arm. }
\end{aligned}
$$

Case 3. A. N., male, age 33 .

extended $5 \mathrm{~cm}$. to the left in the second intercostal space. The patient had had a chancre at the age of 32 , and his blood Wassermann reaction was strongly positive. Under circumstances such as these the presence of a relatively small pulse and low blood pressure in the left brachial artery naturally excited no comment, but there was a lively discussion next day when it was discovered that the inequality had vanished (Figure $1 C$ ). The carotid pulses were equal at all times. The patient did not recover from his cardiac failure, and died of pulmonary embolism. Autopsy disclosed extensive syphilitic aortitis which had encompassed and entered the orifices of the main branches of the aorta, but had not diminished their caliber.

Because of the impossibility of harmonizing such transient disparities as these with any organic lesion we decided to examine a large number of normal persons with the idea of determining the general incidence of significant inequalities in brachial pressures. 


\section{MATERIAL AND METHOD}

The material consisted of a group of 1000 healthy persons, all but a few of whom were university students. No one was included in whom any significant abnormality, particularly of the cardiovascular system, was demonstrable. The group was made up of 731 men and 269 women whose ages ranged from 16 to 49 years, averaging 20 years. The right and left brachial pressures were measured simultaneously with mercury manometers, with the subjects in the sitting posture. Simultaneous measurement was adopted in preference to consecutive in order to avoid the theoretical possibility that application of compressing pressure to one arm might dynamically or reflexly alter the blood pressure in the other, as well as to escape the chance that the arterial pressure might change between successive measurements. The data relating to systolic pressures may be regarded as somewhat more reliable than those which are based in whole or in part on diastolic, for, although all the measurements were made by competent persons, ${ }^{1}$ and care taken to ensure uniform criteria, it is naturally impossible to obtain as high a degree of accuracy with diastolic pressure as with systolic. In addition to the 2000 observations carried out on this group, approximately 1000 measurements were made on 175 patients for the purpose of following transitory disparities and comparing directly the results obtained by simultaneous and consecutive measurements.

\section{RESULTS}

Table I summarizes the inequalities in individual pressure levels, and shows that what we have arbitrarily designated as a significant inequality in brachial systolic or diastolic pressures occurred 439 times; 320, or 73 per cent, ot the higher pressures were dextrolateral. Table II summarizes the incidence of double inequalities, and since every person who appears in this table appears twice in Table $I$, it is obvious that by subtracting the total of Table II, 61, from the total of Table I, 439, we arrive at the percentage incidence of inequality, i.e. 37.8 per cent of 1000 persons. Tabulation by sexes is omitted for the reason that no characteristic difference could be discerned. The incidence of significant disparities in pulse pressure is tabulated separately (Table III) in order to take account of all clinically appreciable inequalities in the volume of the pulse, regardless of whether or not there is a difference of $10 \mathrm{~mm}$. or more between the two systolic or diastolic levels. Table III includes 67 persons who are not represented in Table $I$. The largest disparity in pulse pressures we have seen was $52 \mathrm{~mm}$. (right $90 \mathrm{~mm}$., left $38 \mathrm{~mm}$.); it occurred in a healthy young man not included in the tables.

${ }^{1}$ We wish to express our gratitude to Doctors C. I. Miller, Grace Williams, Margaret K. Butler, F. E. Hambrecht, M. D. Gardner, L. B. Hanson, and D. A. Mathes, and Mr. F. G. Powell, for their willing assistance and cooperation. 
Summary of inequalities in individual brachial pressure levels in 1000 normal persons

\begin{tabular}{|c|c|c|c|c|}
\hline & \multicolumn{2}{|c|}{ Maximum systolic } & \multicolumn{2}{|c|}{ Minimum diastolic } \\
\hline & $R>L$ & $L>R$ & $R>L$ & $L>R$ \\
\hline & $\begin{array}{c}\text { frequency } \\
\text { per cent }\end{array}$ & $\begin{array}{c}\text { frequency } \\
\text { per cent }\end{array}$ & $\begin{array}{c}\text { frequency } \\
\text { per cent }\end{array}$ & $\begin{array}{l}\text { frequency } \\
\text { per cent }\end{array}$ \\
\hline $\begin{array}{l}\text { Inequality of } 10 \mathrm{~mm} . \mathrm{Hg} \ldots \ldots \ldots \ldots \ldots \ldots \ldots \ldots \\
\text { Inequality of } 11 \mathrm{~mm} . \mathrm{Hg} \text { or more } \ldots \ldots \ldots \ldots \ldots\end{array}$ & $\begin{array}{r}7.1 \\
12.2\end{array}$ & $\begin{array}{l}1.6 \\
1.3\end{array}$ & $\begin{array}{l}4.8 \\
7.9\end{array}$ & $\begin{array}{l}4.4 \\
4.6\end{array}$ \\
\hline \multirow{2}{*}{ Total frequency in per cent of 1000 persons.... } & 19.3 & 2.9 & 12.7 & 9.0 \\
\hline & \multicolumn{2}{|c|}{22.2} & \multicolumn{2}{|c|}{21.7} \\
\hline Total frequency of inequalities. . & \multicolumn{4}{|c|}{$439(193+29+127+90)$} \\
\hline Total frequency, $R>L \ldots \ldots \ldots \ldots \ldots$ & \multicolumn{4}{|c|}{$320(193+127)$} \\
\hline Maximal inequality... & $\operatorname{mm}_{32} \mathrm{Hg}$ & $\operatorname{mm}_{16} \mathrm{Hg}$ & $\underset{21}{m m}$ & $\operatorname{mm}_{26} \mathrm{Hg}$ \\
\hline Average inequality $\ldots \ldots \ldots \ldots \ldots \ldots \ldots$ & 12.9 & 11.4 & 12.8 & 12.5 \\
\hline
\end{tabular}

TABLE II

Summary of inequalities in both brachial pressure levels in 1000 normal persons

Concordant inequalities

Maximum systolic and minimum diastolic $R>L \quad L>R$ frequency
per cent
per cent

Inequality of $10 \mathrm{~mm} . \mathrm{Hg}$ or more. ........

0.7

Discordant inequalities

\begin{tabular}{|c|c|c|}
\hline & $\begin{array}{c}R \text { systolic }>L \\
L \text { diastolic }>R \\
\text { frequency } \\
\text { per cent }\end{array}$ & $\begin{array}{c}L \text { systolic }>R \\
R \text { diastolic }>L \\
\text { frequency } \\
\text { per cent }\end{array}$ \\
\hline$y$ of $10 \mathrm{~mm} . \mathrm{Hg}$ or $\mathrm{mc}$ & $\ldots 1.0$ & 0.2 \\
\hline
\end{tabular}

Total incidence of double inequalities: 6.1 per cent of 1000 persons

DISCUSSION

These data challenge the validity of the old assumption of sphygmic equality in the brachial arteries of normal persons, and warn against attaching too much significance to inequality of pulse volume and arterial pressure in patients suspected of having disease of the aorta unless the inequality can be shown to be permanent. Although temporary disparities sometimes persist for days or weeks, they usually disappear within a very much shorter time. Persons who exhibit no inequality at the first examination often show it the next day. The inference is that all people 
TABLE III

Summary of inequalities in pulse pressures in 1000 normal persons

\begin{tabular}{|c|c|c|}
\hline & $R>L$ & $L>R$ \\
\hline & $\begin{array}{l}\text { frequency } \\
\text { per cent }\end{array}$ & $\begin{array}{l}\text { frequency } \\
\text { per cent }\end{array}$ \\
\hline 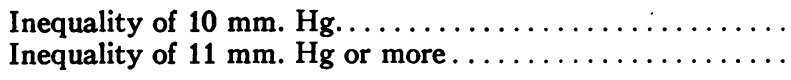 & $\begin{array}{r}6.0 \\
14.1\end{array}$ & $\begin{array}{l}2.8 \\
4.5\end{array}$ \\
\hline \multirow{2}{*}{ Total frequency in per cent of 1000 persons. } & 20.1 & 7.3 \\
\hline & \multicolumn{2}{|c|}{27.4} \\
\hline $\begin{array}{l}\text { Maximal inequality.. } \\
\text { Average inequality... }\end{array}$ & $\begin{array}{c}m m . H_{g} \\
38 \\
14.3\end{array}$ & $\begin{array}{l}\text { mm. } B g \\
32 \\
13.1\end{array}$ \\
\hline
\end{tabular}

manifest sphygmic inequality in the brachial arteries at one time or another-that there is no such thing as permanent sphygmic equality in the arms. In some persons the higher pressure appears to be uniformly homolateral; in others it is shifting continually from one side to the other. The following is an example of discordant heterolateral inequalities in a man 21 years of age with no demonstrable disease of the heart or arteries:

\begin{tabular}{|c|c|c|}
\hline \multirow{2}{*}{$\begin{array}{c}\text { Date } \\
\text { May } 14,1932\end{array}$} & \multicolumn{2}{|c|}{ Brachial blood pressure } \\
\hline & $140 / 50$ & $118 / 80$ \\
\hline 1932 . & $.130 / 80$ & 144 \\
\hline 19 & $.118 / 60$ & $118 / 75$ \\
\hline 9. & $.130 / 80$ & $125 / 50$ \\
\hline
\end{tabular}

Our observations have convinced us that unless one wishes to escape the possibility that the pressure may change between successive measurements little is to be gained by simultaneous estimations. When consecutive measurements are being made it makes no difference which arm is taken first.

Discrepancies in pulse pressure are interesting in themselves, and the perception by palpation of a pulse pressure difference may draw attention to an inequality of pressure levels which would otherwise remain undiscovered, but as long as they exist independently of considerable disparities in systolic and diastolic levels it is difficult to see what signifcance, if any, they have with respect to disease of the aorta.

Speculation as to the cause of sphygmic inequality in normal persons has not been fruitful for the reason that we have been unable to educe a satisfactory explanation which would be equilaterally applicable and at the same time account for the fact that the higher pressure occurs so much more commonly on the right side. Brachial pressures must be determined by both central and peripheral factors; the real problem is to 
discover which of the two is the major factor in any given case of temporary or permanent disparity. Since the maximum pressure may be twice as high in the femoral arteries as in the abdominal aorta (1), one might assume by analogy that the pressure in the innominate artery may exceed that in the ascending aorta, and inasmuch as the high femoral pressure seems to carry over into all the crural arteries at least to the extent that arterial pressure in the legs is generally higher than in the arms (2), one might suppose that in the arms the tendency always is for the pressure to be higher in the right. It would then be necessary to assume in addition a capricious vasomotor factor in order to explain why it is that approximately one-fourth of the higher pressures are sinistral. Theorizing of this kind is of doubtful utility, and unfortunately it is difficult, if not impossible, to attack the problem experimentally.

No attempt was made in this study to relate brachial pressure inequalities to left- or right-handedness, but since the general incidence of left-handedness is approximately 6 per cent (3) it is unlikely that laterality plays any rôle.

\section{LITERATURE}

In view of the frequency with which arterial pressure is measured, and the importance attached to comparatively small departures beyond the accepted limits of normal, particularly by insurance companies, it is surprising that the occurrence of inequalities in brachial pressures has not attracted more attention. Substantially the same statement was made by Phipps (4) seventeen years ago, and it is no less true today. Little or nothing on the subject is to be found in such standard reference works as those of Wiggers (5), Janeway (6), Norris, Bazett, and McMillan (7), Romberg (8), and Edens (9). No one has studied relative pressures in a series of normals as large as that which we are reporting, nor has there been any serious attempt to examine sphygmic inequality as a sign of disease of the aorta in the light of normal controls.

In 1900 Hensen (10) reported that such inequalities as he had discovered by measuring the brachial pressures simultaneously with the Riva Rocci apparatus were negligible; differences of as much as 8 or 10 $\mathrm{mm}$. were unusual, and $18 \mathrm{~mm}$. was the largest he had ever seen. Geisböck (11), in 1905, declared that the pressure should always be measured in both arms because of the fact that considerable disparities often occur. He did not mention the possibility that normal persons might show inequalities, and felt that their presence invariably indicates either organic changes in the vascular system, or permanent disturbances of innervation. A year later Bing (12) described experiments designed to demonstrate the existence of a vasomotor influence on brachial pressure. Incidentally, he compared brachial systolic pressures in ten subjects; $16 \mathrm{~mm}$. $\mathrm{Hg}$ was the largest discrepancy, and the right was usually higher than the left. In 1915 Phipps (4) published an interesting paper. Using an aneroid and a 
$12 \mathrm{~cm}$. cuff, he measured arterial pressures in the arms and legs of 36 patients, some of whom were suffering from disease of the heart or arteries. In only one case did he find the pressure the same in all arteries. In 20 per cent of his cases there was a difference of $10 \mathrm{~mm}$. or more between the brachial pressures, with the higher pressure showing no preference for either side. In one patient with no heart disease and only slight arteriosclerosis (autopsy) there was a difference of $30 \mathrm{~mm}$., whereas a patient with aortic aneurysm had a disparity of only $20 \mathrm{~mm}$. He concluded that the arterial pressure in the two arms may be unequal in normal subjects, that this inequality is not uniform, that the disparity may be as large in young persons with healthy arteries as in old persons with arteriosclerosis, and that "difference between the right and left brachial arteries is by no means diagnostic of aneurysm." He found that placing a layer of fat meat about the arm underneath the cuff did not change the pressure reading, which led him to infer that measurements of brachial pressure are not affected by the thickness of the tissues surrounding the artery. E. F. Cyriax (13) tried to show that unilateral or bilaterally unequal trauma, irrespective of site, produces inequalities in brachial pressures, but his work is invalidated by the fact that such inequalities as he observed may occur in normal persons. Similarly, as Fischer (14) pointed out in 1924, the omission of control observations renders worthless most of the reports of brachial pressure inequalities following hemiplegia, cervical sympathectomy, and unilateral work. Fischer compared brachial systolic and diastolic pressures in 80 unselected patients and found them extremely variable. He never observed a patient who did not show inequality at one time or another. He noted that the pressure in the right arm was not higher in right-handed persons. Except for the fact that in his series the higher pressure was sinistral as often as dextral, Fischer's results differ from ours only quantitatively. He obtained substantially the same results by consecutive and simultaneous measurement. He did not discuss brachial pressure inequalities in relation to disease of the aorta. Mandelstamm (15) busied himself principally with comparing the pressures in the arms and legs. His experience convinced him that consecutive measurements are as reliable as simultaneous. He described briefly two cases of syphilitic aortitis in which the lesion had interfered with the passage of blood into the main branches of the aorta. Bodenstab (16) found a right systolic pressure of $142 \mathrm{~mm}$. $\mathrm{Hg}$, and a left of $112 \mathrm{~mm}$., in a physician whom he was examining for life insurance. This led him to compare brachial pressures in 100 persons who were free from cardiovascular disease. The systolic levels were the same on both sides in only 10 cases, and the diastolic in only 4; the systolic discrepancies ranged from 2 to $46 \mathrm{~mm}$., the diastolic from 2 to $40 \mathrm{~mm}$.; the average systolic inequality was $11.7 \mathrm{~mm}$., the average diastolic $9.6 \mathrm{~mm}$.; and the higher pressures were about equally divided 
between the right and left arms. Van Balen (17) examined 150 young normals and met with only 6 who manifested disparities of more than 10 $\mathrm{mm}$. He expressed the opinion that the left arm is subject to much stronger vasodilator influences than the right, especially when the cervical sympathetic is involved in pathological processes. He also called attention to the fact that the pulse volume may be larger on the side with the lower pressure, presumably because of differences in pulse pressure, although he did not make the point clear with figures in individual cases. Kay and Gardner (18) became interested in the subject when they encountered a candidate for insurance whose right brachial pressure was $165 / 90 \mathrm{~mm}$. $\mathrm{Hg}$, and left $130 / 80 \mathrm{~mm}$. In a series of 125 patients, some of whom had cardiovascular disease, 80 per cent failed to show inequalities larger than $10 \mathrm{~mm}$; the remaining 20 per cent exhibited significant inequalities, and the higher pressure occurred more often on the right side than on the left.

All of the observations referred to above were made with instruments embodying the Riva Rocci principle. In addition, Jellinek (19) and Hirsch (20) studied relative pressures by means of the Gärtner tonometer, and Cawadias (21) and Heitz (22) with the Pachon oscillometer. Because of the difference in instruments we have considered it inadvisable to include their observations.

\section{SUMMARY}

The fact that inequalities in the blood pressure and volume of the pulse in the right and left brachial arteries may or may not indicate disease of the aorta or its branches is illustrated briefly by the presentation of cases.

The data obtained by bilateral brachial pressure measurements in 1000 normal subjects are presented and analyzed. What we have arbitrarily designated as a significant sphygmic inequality occurred 439 times in 378 persons; nearly three-fourths of the higher pressures were dextrolateral. Significant inequalities in pulse pressures appeared in 274 persons, 67 of whom failed to show differences of $10 \mathrm{~mm}$. or more between the two systolic or diastolic levels; nearly three-fourths of the higher pulse pressures were dextrolateral. These pressures were measured simultaneously in both arms, but for all practical purposes consecutive measurement gives equally satisfactory results.

Sphygmic inequality without organic disease is probably always transitory, and it is reasonably certain that all normal persons manifest it at one time or another. The inequality may involve only the systolic pressures, or only the diastolic, or both, and if both levels are disparate the inequality may be concordant (both right higher than both left, or vice versa) or discordant (right systolic higher than the left and left diastolic higher than the right, or vice versa). In some persons the higher pressure is irregularly heterolateral; in others it appears to be 
always homolateral. There is no evidence that right- or left-handedness plays any rôle. The physiology of transitory disparities in brachial pressures is not understood.

Sphygmic inequality in the brachial or carotid arteries cannot be regarded as a sign of disease of the aorta or its branches unless it can be shown to be permanent.

\section{BIBLIOGRAPHY}

1. Wiggers, C. J., The Pressure Pulses in the Cardiovascular System. Longmans, Green and Co., London, 1928, p. 84.

2. Burdick, W., Clarke, N., Garlichs, R., Priestley, J., and Richards, D., Am. J. Physiol., 1925, lxxii, 169. Differences in Blood Pressure in the Arm and Leg in Normal Subjects.

3. Travis, L. E., Personal communication.

4. Phipps, C., Bost. M. and S. J., 1915, clxxiii, 476. Blood Pressure.

5. Wiggers, C. J., Modern Aspects of the Circulation in Health and Disease. Lea and Febiger, Philadelphia, 1923, 2d ed.

6. Janeway, T. C., The Clinical Study of Blood Pressure. Appleton, New York, 1904.

7. Norris, G. W., Bazett, H. C., and McMillan, T. M., Blood Pressure, Its Clinical Applications. Lea and Febiger, Philadelphia, 1927, 4th ed.

8. Romberg, E., Lehrbuch der Krankheiten des Herzens und der Blutgefässe, 4 und 5 Aufl., 1925, Stuttgart, Ferdinand Enke.

9. Edens, E., Die Krankheiten des Herzens und der Gefässe. Julius Springer, Berlin, 1929.

10. Hensen, H., Deutsches Arch. f. klin. Med., 1900, lxvii, 436. Beiträge zur Physiologie und Pathologie des Blutdrucks.

11. Geisböck, F., Deutsches Arch. f. klin. Med., 1905, lxxxiii, 363. Die Bedeutung der Blutdruckmessung für die Praxis.

12. Bing, H. J., Berl. klin. Wchnschr., 1906, xliii, 1650. Ueber die Blutdruckmessung bei Menschen.

13. Cyriax, E. F., Quart. J. Med., 1920, xiii, 148. Unilateral Alterations in Blood Pressure Caused by Unilateral Pathological Conditions: The Differential Blood Pressure Sign.

Quart. J. Med., 1921, xiv, 309. Unilateral Alterations in Blood Pressure: The Differential Blood Pressure Sign. Second Communication.

J. Obst. and Gynec. Brit. Emp., 1922, xxix, 322. Unilateral Blood Pressure Changes in Gynecology and Obstetrics.

14. Fischer, P., Klin. Wchnschr., 1924, iii, 784. Zur Frage differenter Blutdruckwerte im Bereich verschiedener Gefässgebiete beim Menschen.

15. Mandelstamm, M., Deutsches Arch. f. klin. Med., 1926, cliii, 28. Über Blutdruckdifferenzen in verschiedenen Gefässgebieten beim Menschen.

16. Bodenstab, W. H., Journal-Lancet, 1925, xlv, 360. Blood Pressure: Difference of Readings in the Two Arms.

17. Van Balen, G. F., Nederlandsch Tijdschr. v. Geneesk., 1929, lxxiii, 932. Bloeddrukmetingen aan beide armen.

Nederl. Tijdschr. v. Geneesk., 1929, lxxiii, 5861. Het verschil in grootte van den pols aan beide armen in verband met de hoogte van den bloeddruk.

18. Kay, W. E., and Gardner, K. D., Calif. and West. Med., 1930, xxxiii, 578. Comparative Blood Pressures in the Two Arms. Some Clinical Observations. 
19. Jellinek, S., Ztschr. f. klin. Med., 1900, xxxix, 447. Ueber den Blutdruck des gesunden Menschen.

20. Hirsch, K., Deutsches Arch. f. klin. Med., 1901, lxx, 219. Vergleichende Blutdruckmessungen mit dem Sphygmomanometer von Basch und dem Tonometer von Gärtner.

21. Cawadias, A., Compt. rend. de Soc. de biol., 1912, lxxiii, 612. Etude comparative des tensions artérielles des deux membres supérieurs et inférieurs. Applications clinique dans les anévrismes aortique et les artérites des membres inférieurs.

22. Heitz, J., Arch. d. mal. du coeur, 1916, ix, 382. Du niveau de la pression diastolique mesurée au Pachon dans les différentes artères des membres chez les sujets normaux. 